\title{
Climate variability of heat wave and projection of warming scenario in Taiwan
}

\author{
Chuan-Yao $\operatorname{Lin}^{1}$ (D) $\cdot$ Yi-Yun Chien ${ }^{1}$ C Chiung-Jui Su${ }^{1}$ • \\ Mien-Tze Kueh ${ }^{1} \cdot$ Shih-Chun Lung ${ }^{1}$
}

Received: 14 March 2017 / Accepted: 8 October 2017 /Published online: 24 October 2017

(C) The Author(s) 2017. This article is an open access publication

\begin{abstract}
This study examined the climate variability of heat wave (HW) according to air temperature and relative humidity to determine trends of variation and stress threshold in three major cities of Taiwan, Taipei (TP), Taichung (TC), and Kaohsiung (KH), in the past four decades (1971-2010). According to the data availability, the wet-bulb globe temperature (WBGT) heat stress for the three studied cities was also calculated for the past (2003-2012) and simulated under the future warming scenario for the end of this century (2075-2099) using ECHAM5/MPIOM-WRF (ECW) dynamic downscaling 5-km resolution. Analysis showed that past decade (2001-2010) saw increase not only in the number of HW days in all three cities but also in the duration of each HW event in TP and KH. Simulation results revealed that ECW well captures the characteristics of data distribution in these three cities during 2003-2012. Under the A1B projection, ECW yielded higher WBGT in all three cities for 2075-2099. The WBGT in TP indicated that the heat stress for $50 \%$ of the days in July and August by 2075-2099 will be at danger level (WBGT $\geq 31{ }^{\circ} \mathrm{C}$ ). Even the median of WBGT in TC and $\mathrm{KH}\left(30.91\right.$ and $30.88^{\circ} \mathrm{C}$, respectively) are close to $31^{\circ} \mathrm{C}$. Hence, the heat stress in all three cities will either exceed or approach the danger level by the end of this century. Such projection under the global warming trend would necessitate adaptation and mitigation, and the huge impact of dangerous heat stress on public health merits urgent attention for Taiwan.
\end{abstract}

\section{Introduction}

Climate change is the most serious scientific and social challenge in the present century. The rate of increase in annual mean temperature has accelerated (IPCC 2007) with the

Electronic supplementary material The online version of this article (https://doi.org/10.1007/s10584-0172091-0) contains supplementary material, which is available to authorized users.

Chuan-Yao Lin yao435@rcec.sinica.edu.tw

1 Research Center for Environmental “Changes”, Academia Sinica, 128 Sec. 2, Academia Rd, Nangang, Taipei 115, Taiwan, Republic of China 
linear warming trend over the last 50 years $\left(0.13{ }^{\circ} \mathrm{C}\right.$ per decade) almost doubled that for the past century. In recent years, extreme high-temperature events (i.e., heat wave) have frequently been observed around the world, such as in the USA (Davis et al. 2004; Metzger et al. 2010; Smith et al. 2013), Europe (Tertre et al. 2006; Rebetez et al. 2009; Fischer and Schar 2010), and Asia (Ding et al. 2010; Honda et al. 2011; Wang et al. 2016).

Heat wave is a significant environmental hazard which can cause increased deaths and emergency hospital admissions, particularly among vulnerable groups such as elderly people, young children, and patients with chronic diseases (Patz et al. 2005; Kovats and Hajat 2008; Honda et al. 2011; Tong et al. 2010; Parsons 2014). It is estimated by the US National Weather Service that heat-wave days were responsible for more deaths annually than the more dynamic natural disasters such as lightning, floods, hurricanes, and tornadoes. Between 1936 and 1975, about 20,000 US residents died of heat (http://www.nws.noaa.gov/om/hazstats.shtml). Robinson (2001) and Smoyer-Tomic et al. (2003) also indicated that heat wave is a major cause of weather-related deaths. Under the rising trend of global warming, heat wave is expected to increase in frequency, severity, duration, and spatial extent. Hence, it is an urgent need to properly define heat wave so that early warning can be promptly issued. To date, a universal definition of heat wave is lacking because it is strongly related to the weather in an area or the local threshold (Ding et al. 2010; Nairn et al. 2009; Tong et al. 2010). For example, in Canada, a heat wave is defined as three consecutive days when the maximum temperature is $32{ }^{\circ} \mathrm{C}$ or above (Smoyer-Tomic et al. 2003). According to the World Meteorological Organization of the United Kingdom, the definition of a heat wave is "when the daily maximum temperature of more than five consecutive days exceeds the average maximum temperature by $5^{\circ} \mathrm{C}$, the normal period being 1961 to 1990 " (Source: UK Climate Projections; http://nora. nerc.ac.uk/166572/refs). In the USA, the definitions of a heat wave often vary from region to region. The criterion for the issuance of a Heat Advisory by the US National Weather Service is when the heat index is expected to reach $105^{\circ} \mathrm{F}$ for $3 \mathrm{~h}$.

Taiwan, a sub-tropical island in Asia, is susceptible to extreme weather conditions caused by global warming (Lin et al. 2015). The increase in air temperature $\left(\sim 1.4{ }^{\circ} \mathrm{C}\right.$ ) in Taiwan is twice that in the North Hemisphere $\left(\sim 0.7^{\circ} \mathrm{C}\right)$ from 1911 to 2005 (IPCC 2007; Shiu et al. 2009). Chung et al. (2009) examined the impact of heat on mortality in Taipei (1994-2003) found an average increase in respiratory mortality of 9.3\% (range, 4.1$14.8 \%$ ) per $1{ }^{\circ} \mathrm{C}$ increase in surface temperature above $31.5^{\circ} \mathrm{C}$, and an average increase in cardiovascular mortality of $1.1 \%$ (range, $0.3-1.9 \%$ ) per $1{ }^{\circ} \mathrm{C}$ increase in surface temperature above $25.2{ }^{\circ} \mathrm{C}$.

However, the definition of heat wave in Taiwan using temperature alone while neglecting the high relative humidity of the island is far from appropriate. As pointed out by Fischer and Schar (2010), the climatic factors contributing to enhanced morbidity and mortality were a combination of extremely high temperature and relative humidity. In recent studies, the commonly accepted index for estimating heat stress and heat casualty is the wet-bulb globe temperature (WBGT) (Parsons 2006; Gaspar and Quintela 2009; Budd 2008; Stull 2011; Tonouchi et al. 2006). This measure of heat stress in direct sunlight takes into account the temperature, humidity, wind speed, and solar radiation on perception of hot weather. As a matter of fact, ISO 7243 (https://zh. scribd.com/doc/63079476/ISO-7243-Heat-Stress), which is based upon the WBGT, is an accepted international standard that provides a simple method for the assessment and control of hot environments. Originally developed to help control heat casualties, WBGT 
has been found to show better correlation with number of heat stroke patients than air temperature; hence, it has been widely employed in Japan as a standard for estimating heat stress risk.

Besides the inappropriate definition of heat wave, systematic data analysis on climate variability of heat wave and projection of future warming is lacking in Taiwan. The three major cities of Taiwan are Taipei metropolis (TP) (including Taipei City and New Taipei City), Taichung (TC), and Kaohsiung (KH) located respectively in northern, central, and southern Taiwan (Fig. 1). Owing to their unique geographical relief, cities in Taiwan all have their own climate characteristics. Being the capital of Taiwan, TP is surrounded by mountains with the highest peak exceeding $2000 \mathrm{~m}$ in its southeast. More than six million people, about one quarter of the total population of Taiwan, inhabit this small basin of $243 \mathrm{~km}^{2}$ situated at $20-\mathrm{m}$ elevation above sea level. The high population density and complex geographic structure of TP intensifies the UHI effect (Lin et al. 2008, 2011). TC and KH are the largest city in central and southern Taiwan, respectively. The Central Mountain Range with its tallest peak above $3000 \mathrm{~m}$ lies to the east of TC and KH. The total population of both TC and KH exceeded 2.7 million in 2016.

This study reconsiders the prevalent definition of heat wave in Taiwan and examines climate variability of heat-wave days over the past 40 years (1971-2010) to determine the air temperature of critical heat wave. To overcome the problem of unavailable WBGT or erroneous data measured using non-standard instrument (Budd 2008), only the WBGT of TP, TC, and KH between 2003 and 2012 were deduced from available parameters for analysis. Moreover, variations in WBGT under the future A1B warming scenario of the three cities were also deduced using ECHAM5/MPIOM-WRF dynamic downscaling at 5-km resolution. Results of this study would provide important references for policy-makers when evaluating the impact of heat wave on health.

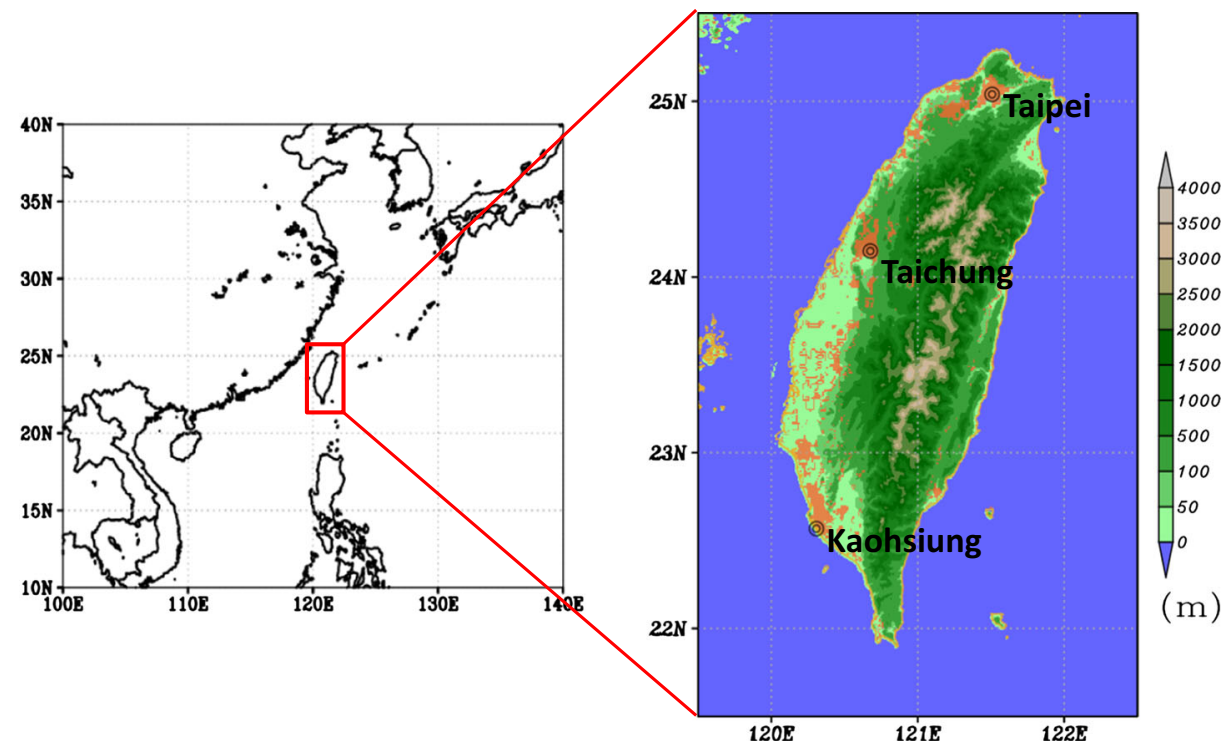

Fig. 1 Topography of Taiwan and location of weather stations in Taipei metropolis (TP), Taichung (TC), and Kaohsiung (KH). Brown color in figure denotes urban and built-up areas 
The rest of the paper is organized as follows. Section 2 describes the data sources, definition of heat wave, and methods for analysis. Section 3 presents the variations in the climate of TP, $\mathrm{TC}$, and KH. Section 4 analyzes the variations of WBGT in the past decades and projections under future warming scenario. Section 5 discusses the projection of WBGT parameters. Section 6 contains the summary and conclusion of this study.

\section{Data sources and heat wave index}

\subsection{Data sources}

To study climate variability, weather data of TP, TC, and KH between 1971 and 2010 were obtained from the Central Weather Bureau (CWB) of Taiwan. While records of air temperature over the four decades were complete, the WBGT for the same period were unavailable. It was from the existing records of air temperature, wind speed, radiation, and relative humidity that the WBGT between 2003 and 2012 were deduced.

For future warming projections, this research focused on the A1B scenario (IPCC 2007) over East Asia. Our previous research (Lin et al. 2015) had performed dynamic downscaling of Taiwan's climate in the recent past (1979-2003) and climate change projection for distant future (2075-2099) using the Weather Research Forecasting (WRF) model. The initial and boundary conditions for WRF simulations were interpolated from the Max Plank Institute Hamburg, global model, ECHAM5/MPIOM (Roeckner et al. 2003). ECHAM5/MPIOM is a global climate model developed by the Max Planck Institute for Meteorology, Hamburg. Output data from the ECHAM5/MPIOM model at 6-h intervals available at the Climate and downscaling system ECHAM5/MPIOM-WRF (hereafter referred to as "ECW") at 5-km resolution. In this study, simulation of meteorological parameters for calculating WBGT of the past (2003-2012) and distant future (2075-2099) were taken from Lin et al. (2015).

\subsection{Heat wave index}

\subsubsection{Temperature}

To reasonably define heat waves in the three studied cities, the top 5\% (i.e., 95 percentile) of daily maximum air temperature in the existing dataset (1971-2010) were taken as the critical heat-wave air temperature. A heat-wave event occurs when the daily maximum air temperature exceed the critical heat-wave air temperature for more than three consecutive days.

\subsubsection{Wet-bulb globe temperature (WBGT)}

According to Tonouchi et al. (2006), the WBGT can be expressed as:

$$
W B G T=0.7 T_{\mathrm{w}}+0.2 T_{\mathrm{g}}+0.1 T_{\mathrm{d}}
$$

where $T_{\mathrm{w}}$ is wet-bulb temperature $\left({ }^{\circ} \mathrm{C}\right), T_{\mathrm{g}}$ is globe temperature $\left({ }^{\circ} \mathrm{C}\right)$, and $T_{\mathrm{d}}$ is dry-bulb temperature $\left({ }^{\circ} \mathrm{C}\right)$. 
As mentioned above, owing to unavailable WGBT from the weather records, $\mathrm{T}_{\mathrm{w}}$ was estimated using the method presented by Stull (2011) with the following empirical expression:

$$
\begin{aligned}
\mathrm{T}_{\mathrm{w}}= & \mathrm{T}_{\mathrm{d}} \operatorname{atan}\left[0.151977(\mathrm{RH} \%+8.313659)^{1 / 2}\right] \\
& +\operatorname{atan}\left(\mathrm{T}_{\mathrm{d}}+\mathrm{RH} \%\right)-\operatorname{atan}(\mathrm{RH} \%-1.676331) \\
& +0.00391838(\mathrm{RH} \%)^{3 / 2} \operatorname{atan}(0.023101 \mathrm{RH} \%)-4.686035
\end{aligned}
$$

where $\mathrm{RH}$ denotes relative humidity.

Similarly, not all weather stations measured $T_{\mathrm{g}}$; hence, it was deduced from dry-bulb temperature, solar radiation, and wind speed following the equation used by Tonouchi et al. (2006):

$$
T_{\mathrm{g}}-T_{\mathrm{d}}=0.017^{*} \mathrm{~S}-0.208^{*} \mathrm{U}
$$

where $S$ is solar radiation $\left(\mathrm{W} / \mathrm{m}^{2}\right)$ and $\boldsymbol{U}$ is wind speed $(\mathrm{m} / \mathrm{s})$.

\section{Climate variability}

\subsection{Temperature}

Figure 2 shows the mean diurnal temperature variation during summer in the three studied cities over the last four decades (1971-2010). As can be seen, between 1971-1980 and 20012010 , there was an increase of $1{ }^{\circ} \mathrm{C}$ at noon but the difference in temperature during nighttime and early morning was even augmented to $2{ }^{\circ} \mathrm{C}$ (Fig. 2a). Similar but slightly weaker warming trend can be observed in TC (Fig. 2b) and KH (Fig. 2c). The extent of warming is lowest in $\mathrm{KH}$, probably due to its coastal location (Fig. 1). TP, with severe impact of urban heat island effect (Lin et al. 2008, 2011), showed the highest extent of warming evidenced by the largest difference in mean diurnal difference in temperature.

Figure 3 shows the frequency of occurrence of air temperature during summer in the studied cities over the last four decades (1971-2010). As can be seen, there was a rightward shift in the curves for both TP (Fig. 3a) and TC (Fig. 3b), more obvious in TP than in TC. During 1971-1980, the temperature with the highest frequency of occurrence was $27^{\circ} \mathrm{C}$ in both TP and TC but it became $29^{\circ} \mathrm{C}$ in TP and $28^{\circ} \mathrm{C}$ in TC during 2001-2010. The respective 2 and $1{ }^{\circ} \mathrm{C}$ increase in most frequently occurred temperature in TP and TC are indicative of a warming trend in these two cities. In contrast, $\mathrm{KH}$ has had $29^{\circ} \mathrm{C}$ as the temperature of the highest frequency of occurrence throughout the past four decades. Nevertheless, warming trend still exists in $\mathrm{KH}$ with such high temperature persisting for longer duration as evidenced by the increasing number of hours with $29{ }^{\circ} \mathrm{C}$ in each decade (Fig. 3c). Frequency of occurrence for temperature for the three cities during 2001-2010 (Fig. 3d) reveals the following. First, TP has the highest frequency of occurrence for temperatures $>34{ }^{\circ} \mathrm{C}$ but the lowest frequency of occurrence for temperatures $<27{ }^{\circ} \mathrm{C}$. In other words, TP has high temperature most of the time due mainly to the urban heat island effect. Second, $\mathrm{KH}$ has the longest duration and highest frequency of occurrence for $29{ }^{\circ} \mathrm{C}$, which is attributed to its southernmost latitude among the three cities. 


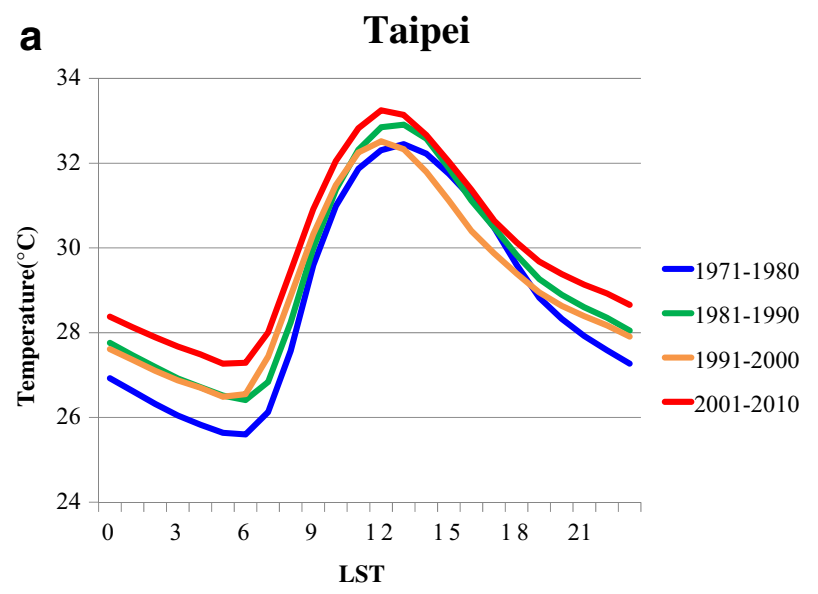

b Taichung

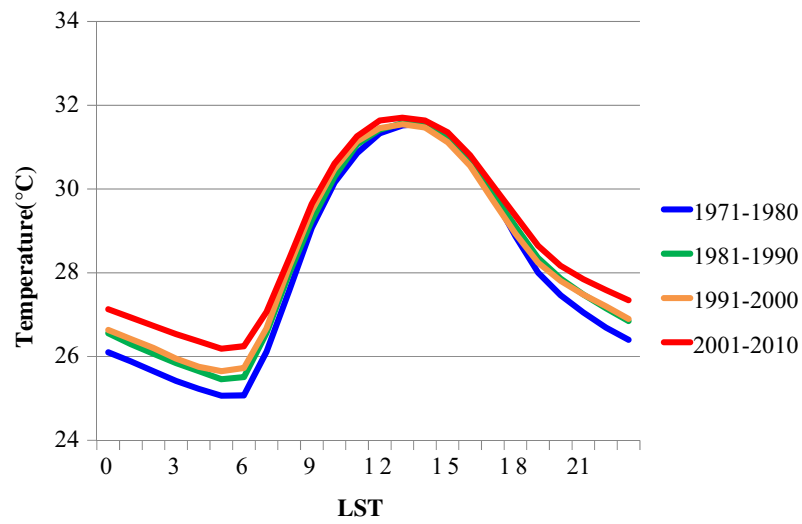

C Kaohsiung

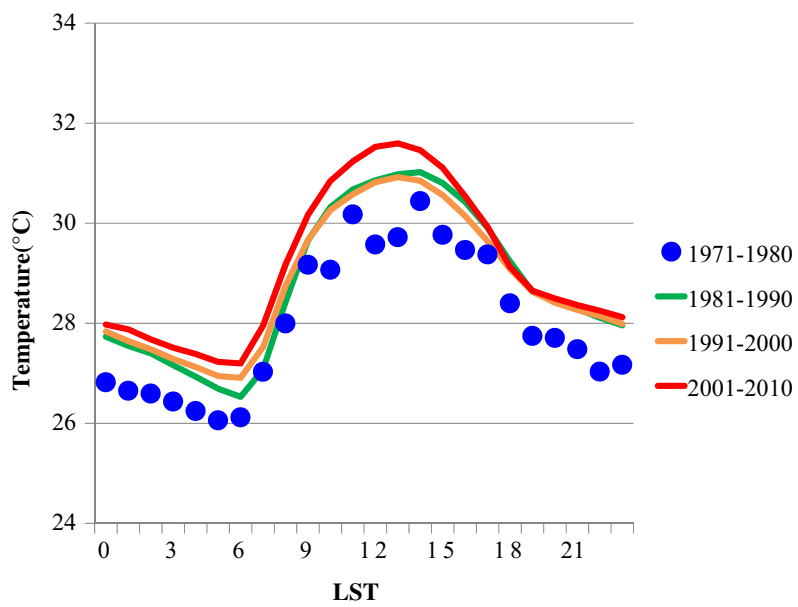

Fig. 2 Mean diurnal temperature variation during July and August in a Taipei, b Taichung, and c Kaohsiung (1971-2010). For Kaohsiung during 1971-1980, only 3-h interval data are available (blue dots in (c)) 

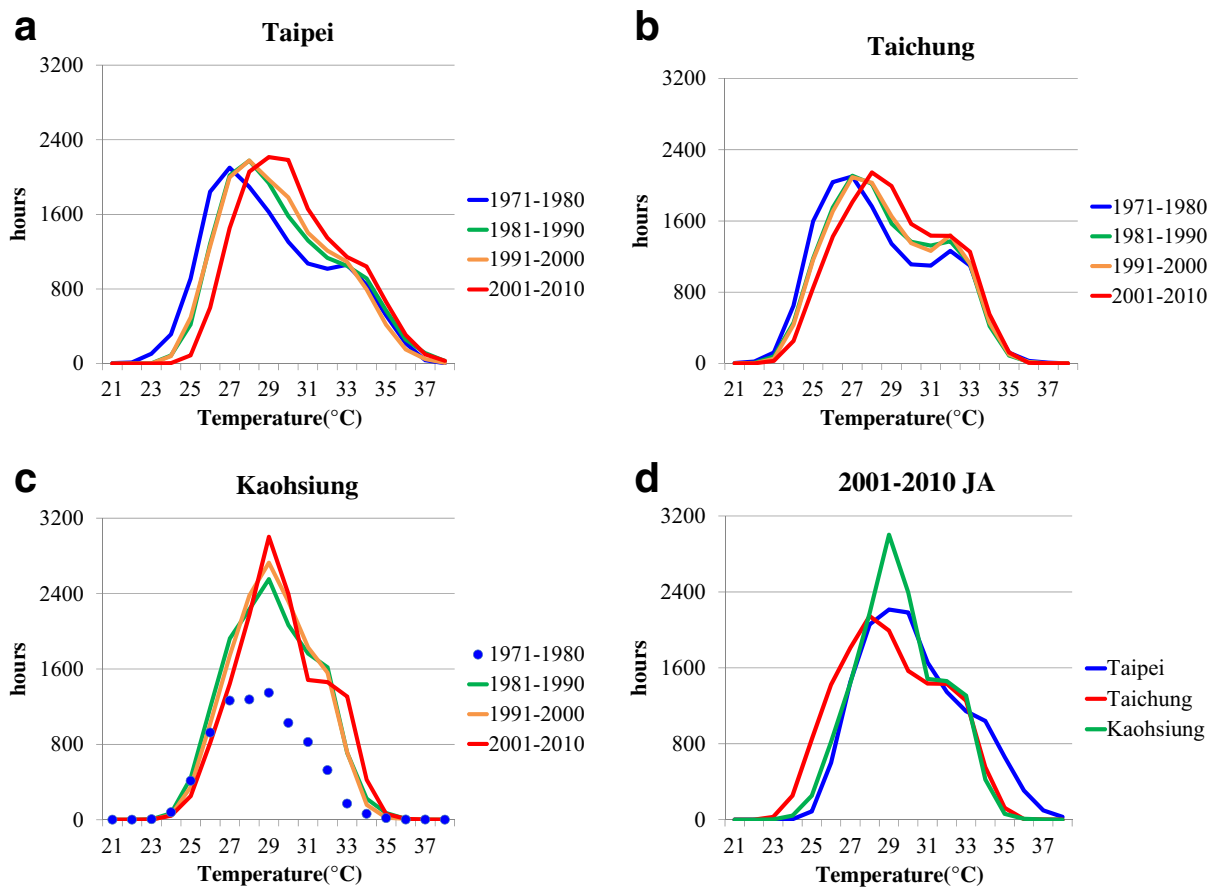

Fig. 3 Frequency of occurrence of air temperature during July and August in a Taipei, b Taichung, c Kaohsiung (1971-2010), and d all three cities studied (2001-2010) For Kaohsiung during 1971-1980, only 3-h interval data are available (blue dots in (c))

\subsection{Relative humidity}

Figure S1 (in the supplementary information) shows the changes in mean relative humidity during July and August from 1971 to 2010 for the three studied cities. As can be seen, there is an obvious declining trend over the past 40 years with mean relative humidity in the order of TP $<\mathrm{TC}<\mathrm{KH}$. Calculations using CWB data from 1971 to 2010 yielded annual mean $\mathrm{RH}$ of 74,77 , and $81 \%$, respectively for the three cities. In general, relative humidity of the entire island is high as it is situated in the subtropical climate zone. KH has the highest RH owing to its coastal location in southwest Taiwan, while TP has the lowest RH due to impact of urban heat island effect. Decrease in relative humidity over the past four decades is strongly related to temperature rise as a result of global warming and change in land use, i.e., urbanization. KH has the largest decrease in relative humidity, exceeding $5 \%$, while the variation in relative humidity for TP over the past four decades is less marked.

Although the physical distances between the three studied cities range between $100 \mathrm{~km}$ and $300 \mathrm{~km}$, they show significant differences in temperature and relative humidity with unique climate characteristics attributed to their distinctive locations, relief, and urban development. In view of the high relative humidity over the entire island of Taiwan, the WBGT heat stress index is considered when examining climate variability of heat wave in Section 4. 


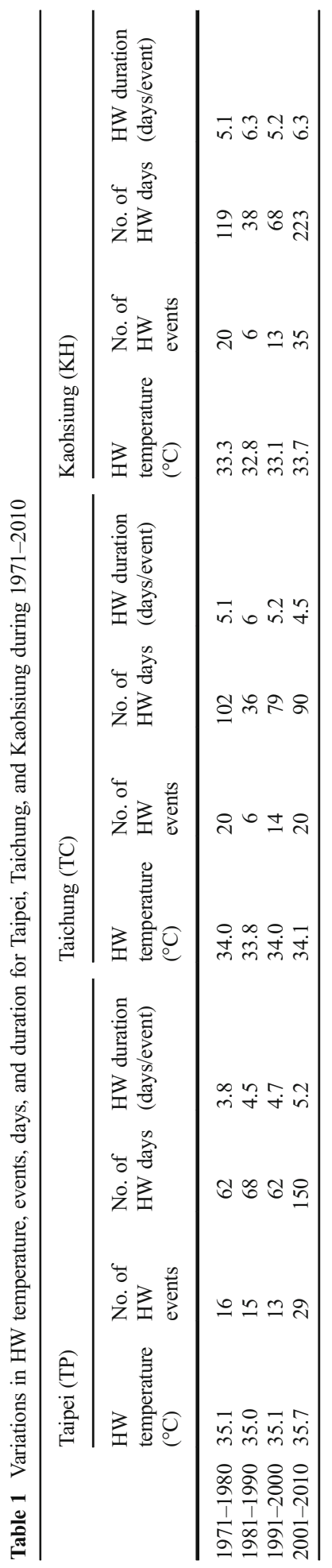




\subsection{Heat-wave temperature and occurrence}

Table 1 details the heat-wave (HW) air temperatures and occurrences for the three studied cities during 1971-2010. As defined in Section 2.2, the critical HW air temperature is the top $5 \%$ (i.e., 95 percentile) of daily maximum air temperature in the existing dataset. As can be seen, the past decade (2001-2010) saw significant increase in HW temperature of $0.6{ }^{\circ} \mathrm{C}$ for both TP and KH. Similarly, marked increase in HW events, days, and duration was also observed for the same time period. For TP, there were $29 \mathrm{HW}$ events over $150 \mathrm{HW}$ days during 2001-2010 as compared with 13-16 HW events over 62-68 HW days in the first three decades (from 1971 to 2000). KH has the highest number of HW events, 35 in 2001-2010, almost tripled that in 1991-2000, and the highest number of HW days, 223 in 2001-2010, more than tripled that in 1991-2000. Not only was there an increase in number of HW days in the past decade, but also the duration of each HW event was on the rise. In $\mathrm{KH}$, the increase was more than 1 day, from 5.2 days/event in 1991-2000 to 6.3 days/event in 2001-2010, while the increase in TP was 0.5 day/event, from 4.7 days/event in 1991-2000 to 5.2 days/event in 2001-2010. For both TP and KH, the past decade saw the greatest increase in HW duration from 1971 through 2010.

Interestingly, while TC showed trend of increase in both HW events and days similar to that observed in TP and $\mathrm{KH}$, the extent is much less. Another contrast is the decrease in HW duration from 5.2 day/event in 1991-2000 to 4.5 days/event in 2001-2010. In fact, HW duration in TC in the past decade was the lowest from 1971 through 2010.

Figure S2 (in the supplementary information) plots the variations in the total number of HW days in the three studied cities during 1971-2010. As seen in the linear trend, KH had the highest rate of increase of 0.32 day/year, followed by TP ( 0.24 day/year) while TC showing insignificant changes. Nevertheless, the mean HW temperature over the last four decades was in the order of $\mathrm{TP}\left(35.2^{\circ} \mathrm{C}\right)>\mathrm{TC}\left(34.0^{\circ} \mathrm{C}\right)>\mathrm{KH}\left(33.2^{\circ} \mathrm{C}\right)$. These results indicated variations in critical HW air temperature and stress threshold among the three studied cities, which would have different implications on public health. As mentioned earlier, using temperature alone is not the best way for estimating heat stress. In view of this, the WBGT heat stress index which takes into account more weather parameters including air temperature, relative humidity, radiation, and wind speed is employed in the following analysis.

\section{Past and projected WBGT heat stress index}

\subsection{Past WBGT heat stress index}

The data in the decade from 2003 to 2012 were taken as the base for analyzing the historical weather record because radiation data were available only after 2003 . With the same method for deducing the critical HW air temperature in each city, the top 5\% of daily maximum WBGT between 2003 and 2012 were calculated. The critical HW WBGT for the three studied cities was in the order of $\mathrm{TP}\left(32.6{ }^{\circ} \mathrm{C}\right)>\mathrm{KH}\left(32.2^{\circ} \mathrm{C}\right)>\mathrm{TC}\left(31.5^{\circ} \mathrm{C}\right)$. Obviously, TP had the highest critical WBGT attributed to its highest air temperature. In terms of critical HW air temperature and WBGT, TP ranked top among the three cities but the ranks for TC and $\mathrm{KH}$ reversed when different HW criteria were used. That is, TC has higher HW temperature than $\mathrm{KH}$ while $\mathrm{KH}$ has higher WBGT temperature than TC. The reason might be the higher annual mean relative humidity during July and August in KH than in TC (see Fig. S1). 

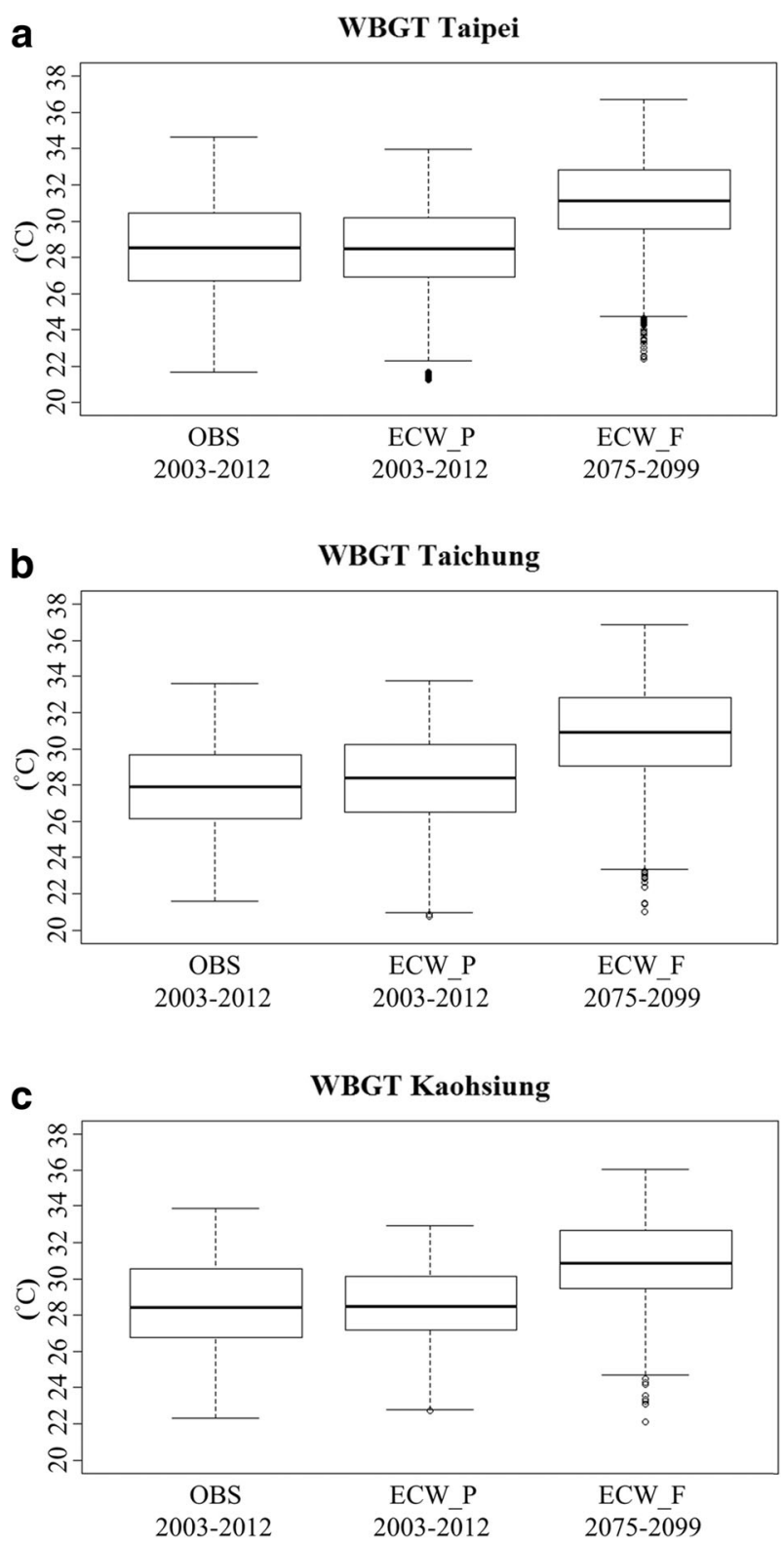

Fig. 4 Box plots of observed (OBS), simulated (ECW_P), and projected (ECW_F) WBGT heat stress indices during July and August for different time periods. a Taipei. b Taichung. c Kaohsiung

According to the guidelines provided by the Japan Sports Association (2006), WBGT $\geq$ $31{ }^{\circ} \mathrm{C}$ means danger for sports and exercise outdoor while WBGT ranging between 28 and $30{ }^{\circ} \mathrm{C}$ is at the alert level. In other words, the WBGT of TP, TC, and $\mathrm{KH}$ have all reached the danger level. Under the current global warming trend, besides air temperature, water vapor is also predicted to be on the rise (Held and Soden 2006). Therefore, the projected WBGT heat stress index during summer time has crucial public health implications. Hence, WBGT heat 


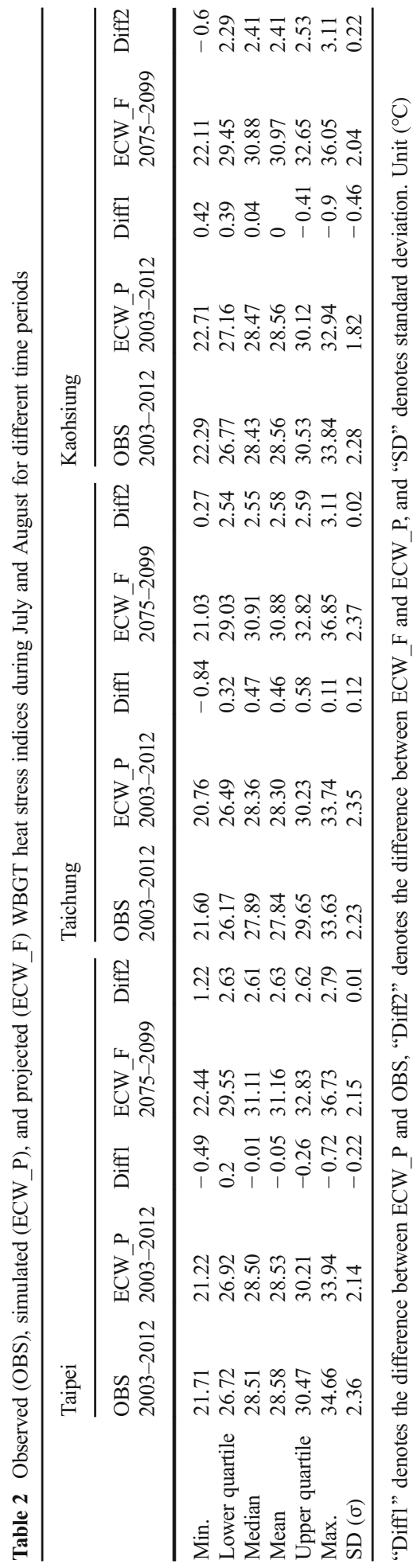


stress indices were calculated using model output data from ECW, and future projections under the warming scenario were also made and discussed in the following section.

\subsection{Projected WBGT heat stress index}

Figure 4 and Table 2 present the observed (OBS) and simulated (ECW_P) WBGT during 2003-2012 and projected WBGT (ECW_F) during 2075-2099 for the three studied cites. As seen in Fig. 4, the simulated results are in general consistent with observed data in TP, TC, and $\mathrm{KH}$. Data listed in Table 2 reveal a slight underestimation in WBGT for TP, with differences between OBS and ECW_P ranging from $-0.01{ }^{\circ} \mathrm{C}$ (median WBGT) to $-0.72{ }^{\circ} \mathrm{C}$ (max. WBGT). In contrast, a slight overestimation in WBGT was observed in TC, with differences between OBS and ECW_P ranging from $0.11{ }^{\circ} \mathrm{C}$ (max. WBGT) to $0.58{ }^{\circ} \mathrm{C}$ (upper quartile WBGT). Similarly, the deduced results for $\mathrm{KH}$ also showed a slight overestimation, with differences between OBS and ECW_P ranging from $0.04{ }^{\circ} \mathrm{C}$ (median WBGT) to $0.42{ }^{\circ} \mathrm{C}$ (min. WBGT). In other words, the difference between observed and deduced WBGT was in the order of $\mathrm{TP}>\mathrm{TC}>\mathrm{KH}$, with the overestimation in $\mathrm{KH}$ less than $0.5^{\circ} \mathrm{C}$ and that in TP less than $1{ }^{\circ} \mathrm{C}$. Taken together, these results reveal that ECW well captures the characteristics of data distribution in these three cities during 2003-2012. In view of its good simulation performance, ECW was employed to project future WBGT in these three cities during 2075-2099.

Under the A1B projection, ECW yielded higher WBGT in all three cities for 20752099, that is, ECW_F > ECW_P in TP, TC, and KH as seen in Fig. 4. Data listed in Table 2 reveal that the differences between ECW_P (2003-2012) and ECW_F (2075-
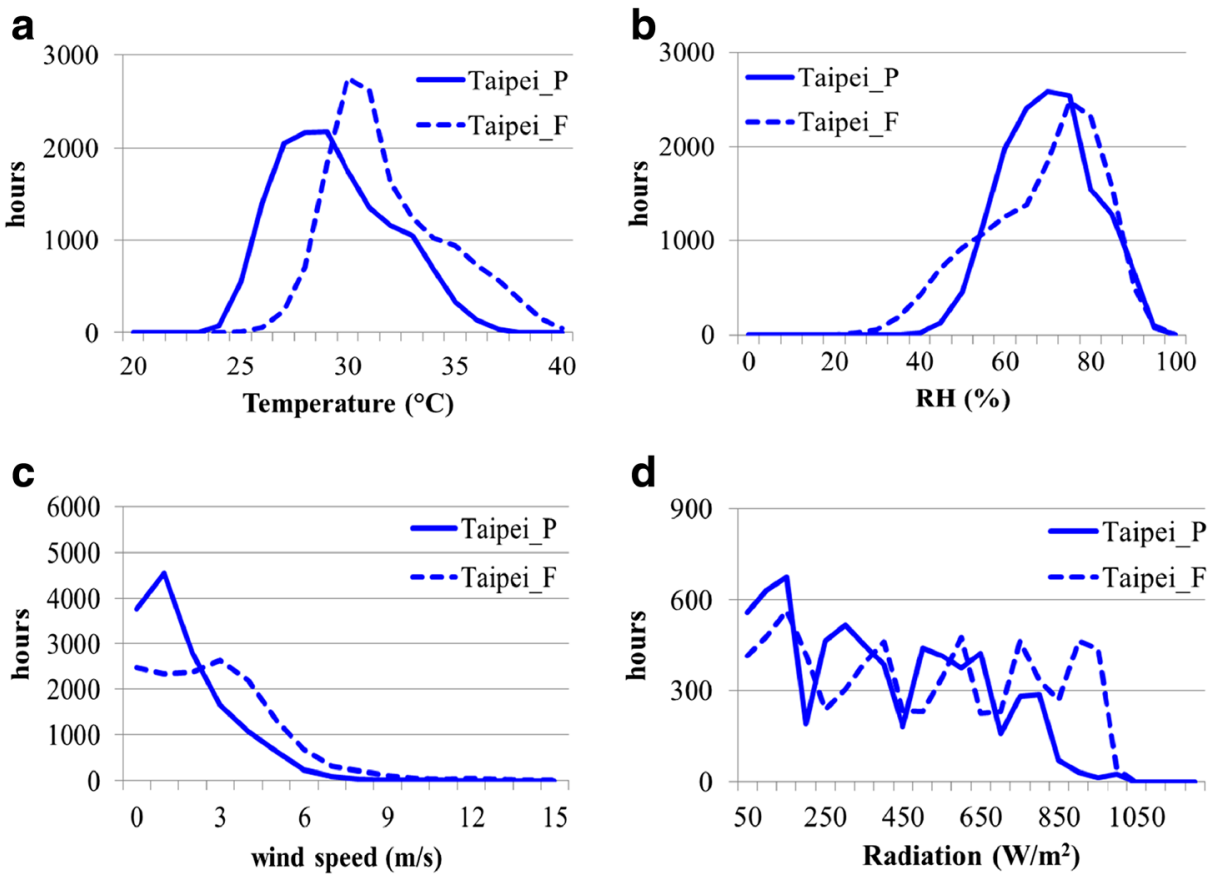

Fig. 5 Frequency of occurrence and changes in a air temperature, $\mathbf{b}$ relatively humidity, $\mathbf{c}$ wind speed, and $\mathbf{d}$ radiation in Taipei between past (2003-2012, Taipei_P) and future (2075-2084, Taipei_F) 


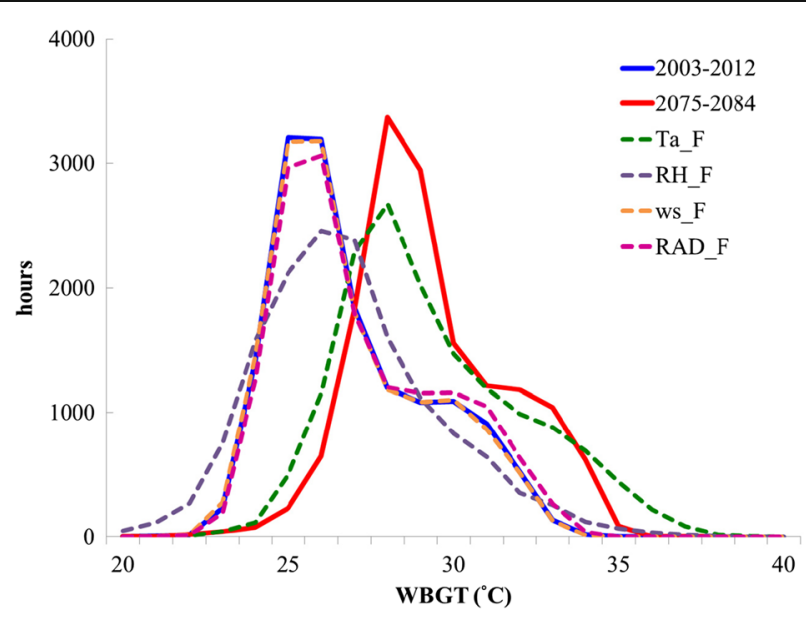

Fig. 6 Frequency of occurrence and changes in WBGT in Taipei between past (2003-2012, blue solid) and future (2075-2084, red solid) with respective projected air temperature (green dashed), RH (purple dashed), wind speed (orange dashed), and radiation (pink dashed)

2099) are ranging from $1.22{ }^{\circ} \mathrm{C}$ (min WBGT) to $2.79{ }^{\circ} \mathrm{C}(\max$. WBGT) for $\mathrm{TP}$, from $0.27{ }^{\circ} \mathrm{C}$ (min WBGT) to $3.11^{\circ} \mathrm{C}$ (max. WBGT) for TC, and $-0.6{ }^{\circ} \mathrm{C}$ (min WBGT) to $3.11{ }^{\circ} \mathrm{C}$ (max. WBGT) for KH. It is interesting to note that the minimum WBGT is projected to decrease for $\mathrm{KH}$, the only exception among all projections. Overall, the increase in WBGT was in the order of $\mathrm{TP}>\mathrm{TC}>\mathrm{KH}$ with the exception of maximum WBGT being $\mathrm{TC}=\mathrm{KH}>\mathrm{TP}$.

As mentioned earlier, WBGT $\geq 31{ }^{\circ} \mathrm{C}$ denotes a danger level. As seen in Table 2, the median WBGT in TP was 31.11, implying that the heat stress for $50 \%$ of the days in July and August by 2075-2099 will be at the danger level. Even the projected median WBGT in TC and $\mathrm{KH}$ (30.91 and $30.88^{\circ} \mathrm{C}$, respectively) are both close to $31^{\circ} \mathrm{C}$. That is to say, by the end of this century, the heat stress in all three cities will either exceed or approach the danger level. Such projection under the global warming trend would necessitate adaptation and mitigation for Taiwan. Needless to say, the huge impact of dangerous heat stress on public health merits urgent attention.

\section{Projection of WBGT parameters}

As seen in Eqs. (1)-(3), calculating the WBGT heat stress index involves different parameters, namely air temperature, relative humidity, radiation, and wind speed. Figure 5 displays the projected changes in individual parameters under the future warming scenario for TP. Seen in Fig. 5a is an obvious rightward shift in air temperature, revealing increases in minimum and maximum temperature by 2 and $3{ }^{\circ} \mathrm{C}$, respectively from 2003 to 2012 to 2075-2084. Not only will future air temperature increase, there will also be longer hours with high air temperature under the current global warming trend. As for projected changes in RH shown in Fig. 5b, the frequency of low RH is decreasing while that of high RH remains almost the same. Frequency of both high wind speed $(3-8 \mathrm{~m} / \mathrm{s})$ and strong radiation $\left(>700 \mathrm{w} / \mathrm{m}^{2}\right)$ are also projected to increase, as seen in Fig. 5c, d, respectively. 
Figure 6 plots the past WBGT in TP during 2003-2012 and the future WBGT calculated with the projection of each and all four parameters taken into account. As can be seen, there is an obvious rightward shift of the future WBGT, indicating projected increase in WBGT. Moreover, the projected temperature curve (green dashed line) approximates the projected WBGT of 2075-2084, with the peak WBGT value even higher than the future maximum air temperature. Comparatively, projection of the other three parameters has little impact on effecting changes in WGBT. Future WGBT calculated with projected RH (purple dashed line), wind speed (orange dashed line), and radiation (pink dashed line) resembled the past WGBT of 2003-2012 (blue solid line) showing minor or no changes. Hence, it can be concluded that air temperature is the dominant parameter influencing the future WBGT. The current global warming trend causes the effect of other parameters on WBGT to be relatively insignificant.

\section{Summary and conclusion}

Heat wave, as a major cause of weather-related deaths, has been responsible for more deaths annually than natural disasters in many parts of the world. It also has significant health impact on Taiwan. Hence, evaluating the changes in heat-wave temperature and occurrence under the global warming trend is of both need and urgency.

This study first defined HW events in the three major cities of Taiwan using the top 5\% (i.e., 95 percentile) of daily maximum air temperature in the existing dataset during 1971-2010 as the critical HW air temperature. Results showed that the past decade (2001-2010) saw significant increase in HW temperature of $0.6{ }^{\circ} \mathrm{C}$ for both TP and $\mathrm{KH}$. In fact, not only was there an increase in number of HW days in the past decade, but also the duration of each HW event was on the rise in TP and $\mathrm{KH}$. The mean $\mathrm{HW}$ temperature over the last four decades was in the order of $\mathrm{TP}\left(35.2{ }^{\circ} \mathrm{C}\right)>\mathrm{TC}\left(34.0^{\circ} \mathrm{C}\right)>\mathrm{KH}\left(33.2^{\circ} \mathrm{C}\right)$. TC showed trend of increase in both HW events and days similar to that observed in TP and $\mathrm{KH}$, though of a much smaller extent in 2001-2010. The three studied cities revealed variations in critical HW air temperature and stress threshold which would have different implications on public health.

WBGT has been found to show better correlation with number of heat stroke patients than air temperature. According to data availability, the WBGT heat stress for the three studied cities in Taiwan was calculated for the past (2003-2012) and simulated under the future warming scenario for the end of this century (2075-2099) using ECHAM5/ MPIOM-WRF (ECW) dynamic downscaling 5-km resolution. Simulation results were in general consistent with observed data in TP, TC, and $\mathrm{KH}$. The difference between observed and deduced WBGT was in the order of $\mathrm{TP}>\mathrm{TC}>\mathrm{KH}$, with a slight overestimation found in $\mathrm{KH}$ and TP. In other words, ECW well captures the characteristics of data distribution in these three cities during 2003-2012. Under the A1B projection, ECW yielded higher WBGT in all three cities for 2075-2099. The WBGT in TP indicated that the heat stress for $50 \%$ of the days in July and August by 2075-2099 will be at a danger level (WBGT $\geq 31^{\circ} \mathrm{C}$ ). Even the projected median WBGT in TC and $\mathrm{KH}\left(30.91\right.$ and $30.88{ }^{\circ} \mathrm{C}$, respectively) are close to $31{ }^{\circ} \mathrm{C}$. That is, the heat stress in all three cities will either exceed or approach the danger level by the end of this century. Such projection under the global warming trend would necessitate the adaptation and mitigation for Taiwan. Needless to say, the huge impact of dangerous heat stress on public health merits urgent attention. 
Acknowledgments This work was financially supported by the Ministry of Science and Technology, Taiwan under grants, 105-2621-M-001-002, 105-2111-M-001-003, and the thematic project of Academia Sinica, Taiwan under grants AS-105-SS-A02 and AS-104-SS-A02.

Open Access This article is distributed under the terms of the Creative Commons Attribution 4.0 International License (http://creativecommons.org/licenses/by/4.0/), which permits unrestricted use, distribution, and reproduction in any medium, provided you give appropriate credit to the original author(s) and the source, provide a link to the Creative Commons license, and indicate if changes were made.

\section{References}

Budd GM (2008) Wet-bulb globe temperature (WBGT) — its history and its limitations. J Sci Med Sport 11:20-32

Chung JY, Honda Y, Hong YC, Pan XC, Guo YL, Kim H (2009) Ambient temperature and mortality: an international study in four capital cities of East Asia. Sci Total Environ 408:390-396

Davis RE, Knappenberger PC, Michaels PJ, Novicoff WM (2004) Seasonality of climate-human mortality relationships in US cities and impacts of climate change. Clim Res 26:61-76

Ding T, Qian W, Yan Z (2010) Changes in hot days and heat waves in China during 1961-2007. Int J Climatol 30:1452-1462. https://doi.org/10.1002/joc.1989

Fischer EM, Schar C (2010) Consistent geographical patterns of changes in high-impact European heatwaves. Nat Geosci 3:398-403. https://doi.org/10.1038/NGEO866

Gaspar AR, Quintela DA (2009) Physical modelling of globe and natural wet bulb temperatures to predict WBGT heat stress index in outdoor environments. Int J Biometeorol 53:221-230. https://doi.org/10.1007 /s00484-009-0207-6

Held IM, Soden BJ (2006) Robust responses of the hydrological cycle to global warming. J Clim 19:5686-5699

Honda Y, Sugimoto K, Ono M (2011) Adaptation to climate change at population level in Japan. Epidemiology 22(issue 1):S26. https://doi.org/10.1097/01.ede.0000391738.93182.aa

IPCC (2007) Climate change (2007) the physical science basis. In: Solomon S, Qin D, Manning M, Chen Z, Marquis $\mathrm{M}$ et al (eds) Contribution of working group I to the fourth assessment report of the intergovernmental panel on climate change. Cambridge University Press, Cambridge 996 pp

Japan Sports Association (2006) Guidelines for the prevention of heat disorder during sports activities. 2nd version, 48 pp (in Japanese)

Kovats RS, Hajat S (2008) Heat stress and public health: a critical review. Annu Rev Publ Health 29:41-55

Lin CY, Chen F, Huang J, Liou YA, Chen WC, Chen WN, Liu SC (2008) Urban heat island effect and its impact on boundary layer development and land-sea circulation over northern Taiwan. Atmos Environ 42:5639-5649

Lin CY, Chen WC, Chang PL, Sheng YF (2011) Impact of urban heat island effect on the precipitation over complex geographic environment in northern Taiwan. J Appl Meteorol Clim 50:339-353. https://doi. org/10.1175/2010JAMC2504.1

Lin CY, Chua YJ, Sheng YF, Hsu HH, Cheng CT, Lin YY (2015) Altitudinal and latitudinal dependence of future warming in Taiwan simulated by WRF nested with ECHAM5/MPIOM. Int J Climatol 35:1800-1809. https://doi.org/10.1002/joc.4118

Metzger KB, Ito K, Matte TD (2010) Summer heat and mortality in New York city: how hot is too hot? Environ Health Perspect 118:80-86. https://doi.org/10.1289/ehp.0900906

Nairn J, Fawcett R, Ray D (2009) Defining and predicting excessive heat events, a national system. Understanding High Impact Weather, CAWCR Modelling Workshop, 30 Nov to 2 Dec, 2009

Parsons K (2006) Heat stress standard ISO7243 and its global application. Ind Health 44:368-378

Parsons K (2014) Human thermal environments: the effects of hot, moderate, and cold environments on human health, comfort, and performance. CRC Press, Boca Raton

Patz JA, Lendrum DC, Holloway T, Foley JA (2005) Impact of regional climate change on human health. Nature 438:310-317. https://doi.org/10.1038/nature04188

Rebetez M, Dupont O, Giround M (2009) An analysis of the July 2006 heatwave extent in Europe compared to the record year of 2003. Theor Appl Climatol 95:1-7

Robinson PJ (2001) On the definition of a heat wave. J Appl Meteorol Clim 40:762-775

Roeckner E, Bauml G, Bonventura L, Brokopf R, Esch M et al (2003) The atmospheric general circulation model ECHAM5/MPIOM. Part I: model description. Report no. 349. Max Planck Institute for Meteorology, Hamburg

Shiu CJ, Liu SC, Chen JP (2009) Diurnally asymmetric trends of temperature, humidity and precipitation in Taiwan. J Clim 22:5639-5649. https://doi.org/10.1175/2009JCLI2514.1 
Smith TT, Zaitchik BF, Gohlke JM (2013) Heat waves in the United States: definitions, patterns and trends. Clim Chang 118:811-825. https://doi.org/10.1007/s10584-012-0659-2

Smoyer-Tomic KE, Kuhn R, Hudson A (2003) Heat wave hazards: an overview of heat wave impact in Canada. Nat Hazards 28:465-486

Stull R (2011) Wet-bulb temperature from relative humidity and air temperature. J Appl Meteorol Clim 50:2267-2269

Tertre L, Alain A, Lefranc D, Eilstein C, Declercq S et al (2006) Impact of the 2003 heatwave on all-cause mortality in 9 French cities. Epidemiology 17:75-79. https://doi.org/10.1097/01.ede.0000187650.36636.1f

Tong S, Wang XY, Barnett AG (2010) Assessment of heat-related health impacts in Brisbane, Australia: comparison of different heatwave definitions. PLoS One 5(8):e12155. https://doi.org/10.1371/journal. pone. 0012155

Tonouchi M, Murayama K, Ono M (2006) WBGT forecast for prevention of heat stroke in Japan. Sixth Symposium on the Urban Environment, American Meteorological Society, Section PJ1.1

Wang L, Wu Z, Wang F, Du H, Zong S (2016) Comparative analysis of the extreme temperature event change over Northeast China and Hokkaido, Japan from 1951 to 2011. Theor Appl Climatol 124:375-384 